\begin{tabular}{|c|c|c|}
\hline $\begin{array}{l}\text { An International Biannual Open Access } \\
\text { Peer-Reviewed/Refereed Journal } \\
\text { JOURNAL OF GLOBAL RESOURCES } \\
\text { Published by : ISDESR, Jaipur, India }\end{array}$ & 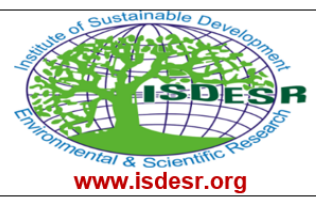 & $\begin{array}{r}\text { ISSN: } 2395-3160 \text { (Print) } \\
\text { ISSN: } 2455-2445 \text { (Online) } \\
\text { January } 2022, \text { Volume } 08(01) \\
\text { DOI Prefix: } 10.46587 / J G R\end{array}$ \\
\hline
\end{tabular}

17

\title{
DIMENSIONS OF URBANIZATION AND POPULATION TRENDS IN NAGAUR CITY
}

\author{
Sandhya Pathania ${ }^{1}$ and Ankit $^{2}$ \\ ${ }^{1}$ Associate Professor, ${ }^{2}$ Research Scholar, \\ Department of Geography, Government Meera Girls College, Udaipur (Rajasthan) India \\ Email: drspathania@gmail.com, ankitvaishnav2020@gmail.com
}

Pathania, Sandhya and Ankit (2022) Dimension of urbanisation and population trends in Nagaur city, Journal of Global Resources, Vol. 08 (01)

DOI:

10.46587/JGR.2022.v08i01.017

Received: 25 Nov. 2021

Reviewed: 11 Dec. 2021

Revised: 20 Dec. 2021

Final Accepted: 26 Dec. 2021

OPEN O A C C S S

Freely available Online www.isdesr.org

\begin{abstract}
This paper attempts to analyse the trends of urbanization based on three-decade census data during 1991, 2001, and 2011 in Nagaur city. Various dimensions of urbanization have been studied through charts and diagrams. For this purpose, the urban parameters such as the growth rate of the urban population, gender dynamics, literacy rate, density, work, and economic structure of the Nagaur city have been examined. Results show that in these last three decades the urban structure of Nagaur city has been changed due to rapid industrialization and rural to urban migration. Urbanization in Nagaur has been relatively slow compared to many developing megacities. As per data released by Govt. of India, Nagaur is an Urban Agglomeration coming under the category of Class I UAs/Towns. According to trends, Nagaur is at the acceleration stage of the process of urbanization. Rapid urbanization raises many issues that might have both positive and negative impacts on the environment. In this situation, monitoring urbanization is vital for planners, management, government, and non-government organizations for implementing policies to optimize the use of natural resources and accommodate development at the same time minimizing the impact on the environment.
\end{abstract}

Key Words: Trends of Urbanization, Urban Study, Dimensions of Urbanization. 


\section{Introduction}

The word urbanization simply means 'the process of making an area more urban'. It is a longterm continuous process. It is a progressive concentration of the population in urban units (Davis, 1965). Urbanization is a process that has been going on for centuries. It shows the increase in the population of the cities. It is a concept related to modernization, industrialization, and globalization. Although, it is not a modern phenomenon. In ancient history, Roman, Greek, Egypt, and the Harappan civilization were known for their large cities. The distinctive feature of the Harappan civilization is urban planning. They are the first to build planned cities. Also, ancient cities of India like Patana, Kannauj, Varanasi, Ujjain, and Madurai, etc. were the canters of economic, social, cultural, and political activity. According to the 2018 Revision of World Urbanization Prospects produced by the Population Division of the UN Department of Economic and Social Affairs (UNDESA), Globally, 55 percent of the world's people live in cities as of 2018. Which was 30 percent in 1950 and is expected to increase to 68 percent by 2050 . Together India, China, and Nigeria will account for 35 percent of the projected growth of the world's urban population between 2018 and 2050. In North and South America, more than 80 percent of the population lives in cities. The level of urbanization in Asia is now approximately 50 percent. On the other hand, only 43 percent of the population in Africa is urban. Thus, the study of urbanization became an integral part of human settlement. The number of the total population has increased from 23.84 crores in 1901 to 102.7 crores in 2001 whereas the number of populations residing in urban areas has increased from 2.58 crores in 1901 to 37.7 crores in 2011 . As per the 2011 census, 31.16 percent of India's population is urban. The urbanization of India has taken place in many phases. Urbanization increased in India since liberalization but the number of mega-sized urban clusters has remained almost constant over the years. Although there is a rapid increase in the small urban towns. During the past 140 years, India has experienced remarkable land-use and land-cover changes including deforestation, cropland changes, and urban expansion (Roy et al., 2015). The level of urbanization in India increased from 27.81 percent in the 2001 Census to 31.16 percent in the 2011 Census. The number of metropolitan cities having a million-plus population has increased from 35 to 53 .

\section{Objective}

- To understand the conceptual framework of Urbanization.

- To analyze the trend of urbanization in Nagaur City.

\section{Methodology}

For this study, three decadal demographic data of Nagaur have been obtained from the District Census Handbook. Comparative study of these three decadal data has been done with the help of different diagrams.

\section{Conceptual Framework}

Urbanization simply means the movement of the population towards urban areas from rural areas. It is a gradual increase in the proportion of people living in urban areas. In contemporary times urbanization is the reality of developing nations. Moreover, people mostly add to urbanization due to work opportunities and better living standards. Urbanization is the biggest feature of economic progress. The process of urbanization depends on the growth of some industrialized urban canters as well as the migration of surplus populations from rural to urban areas.

The following parameters have been adopted in the census to define urban areas: -

(a) All places with a Municipality, Corporation or Cantonment or Notified Town Area.

(b) All other places which satisfied the following criteria:

(i) A minimum population of 5,000 . 
(ii) Where 75 percent of the male population residing in the area is engaged in nonagricultural activities.

(iii) Density of population at least 400 sq. km. (i.e., 1000 per sq. Mile)

Urban areas are much more efficient in terms of the economy than rural areas. Important and basic amenities like education, health, water is easily available in urban areas. It is very easy to access basic services in cities as compared to rural areas. Most notable, these services are high-quality education, specialist health care, convenient transportation, entertainment, etc. In addition, some or all services are unavailable in rural areas. Urban areas provide better employment opportunities. Rapid industrialization and commercialization resulted in various employment opportunities. Urban areas play an important role as a producer and dissemination of knowledge. It is because of the highly connected urban world. Most notable, the geographical proximity of people in urban areas helps in the spread of ideas. Technological development also comes first in urban areas. A variety of technologies are applied in urban areas. If we try to understand the reasons for urban growth then we found that first, political reasons play a big role in urbanization. Many families move to urban areas in search of food, shelter, and employment. Another important reason for urbanization is economic. Poverty and administrative distance have been characteristics of rural areas. Farmers find it very difficult to earn enough profit and livelihood. As a result, rural people move to urban areas in search of better employment opportunities. Education, medical and other facilities are a strong cause of urbanization. In addition, Urbanization has increased as a result of industrialization. The young population of the villages migrates to the urban areas in search of a better lifestyle. Moreover, the conservative culture of rural areas pushes the youth towards the cities. Urban areas offer a liberal lifestyle to the youth. Cities have attracted youth towards them with their dazzle and facilities. The healthy aspect of rapid industrialization has led to the establishment and development of many industrial cities. Along with manufacturing units, ancillary and service sectors began to grow in those urban areas. But with this there are some negative aspects as well for example the growth of the economy is closely linked to urbanization, it has created some serious problems. Firstly, increasing urbanization is largely responsible for the increasing congestion in urban areas. Overcrowding has led to problems like traffic jams, the management of which is gradually becoming very difficult and costly. Secondly, overpopulation is another unhealthy aspect of urbanization that creates urban chaos related to urban housing, education, medical facilities, development of slums, unemployment, violence, overcrowding, etc. All these results in deterioration in the quality of human life. Finally, as a result of urbanization, mass migration takes place from rural to urban areas. Such large-scale migration of the active population from rural areas will lead to a reduction in productivity in rural areas, which will worsen the condition of the rural economy. Thus, urbanization, beyond a certain point, will have unhealthy consequences. That is why it becomes very important to understand and know about urbanization.

\section{Study Area}

Nagaur is a city located in the state of Rajasthan. It serves as the administrative headquarters of the Nagaur district. It is located almost in the middle of Rajasthan It is part of the Marwar region of Rajasthan and is known as the heart of Rajasthan. Nagaur city is geographically located between $27^{\circ} 16^{\prime} \mathrm{N}$ to $27^{\circ} 23^{\prime} \mathrm{N}$ Latitude and $73^{\circ} 69^{\prime} \mathrm{E}$ to $73^{\circ} 77^{\prime} \mathrm{E}$ Longitude. The area of Nagaur city is $37 \mathrm{~km} 2$. It is $262 \mathrm{~km}$ away from the capital Jaipur. It is a dry and desert region. If we talk about the climatic conditions, then there is an average annual rainfall of $310 \mathrm{~mm}$. The average temperature during summer is $40^{\circ}$ to $28^{\circ}$ while in winter the average temperature is $22^{\circ}$ to $6^{\circ}$. The NH62 and NH58 pass through the city. There are 60 wards in the city.(Figure-1) 
Figure 01: Location of Study Area

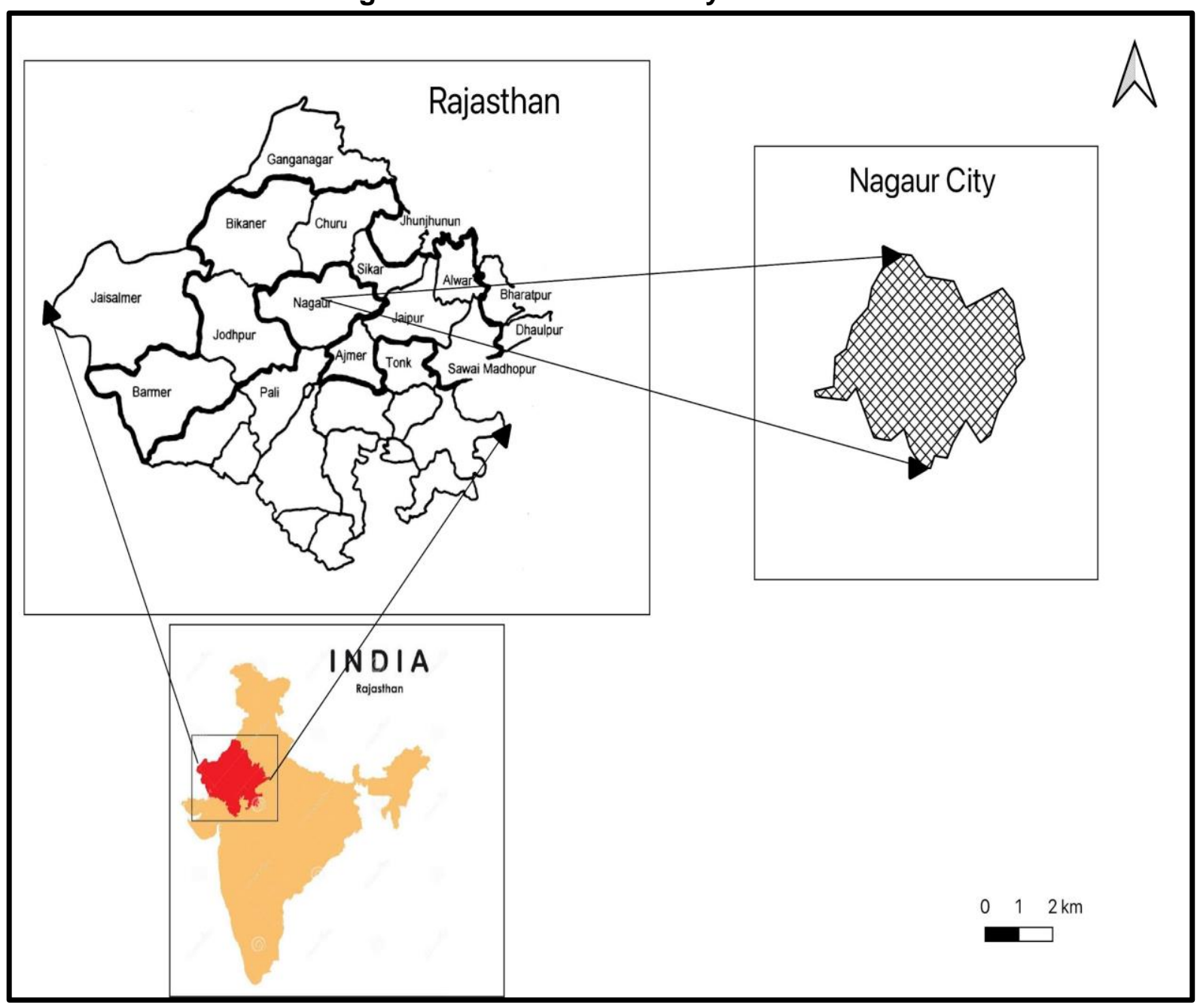

\section{Analysis}

In this section, we will analyse the different trends related to urban growth in Nagaur City. Data from District Census Handbooks have been used in writing this paper. The data obtained from this has been thoroughly analysed and this analysis has been presented through various charts. The series of District Census Handbooks have been prepared after scanning and processing the data collected through House List Schedule and Household Schedule. It was published by the directorate of census operation, Rajasthan.

\section{Population Structure}

If we talk about the population structure, then in 1991 the population of Nagaur was 68,194 . which increased to 93,915 by 2001 . The increase in population continued even further, by 2011 it increased to $1,05,218$. In 2011 the population of Nagaur city was 3.18 percent of the population of the entire Nagaur district. Between1991 and 2001, 25,721 people were added to the population, and between 2001 to 2011, 11,303 persons were added. So, it can be said that between 2001 and 2011 the rate of growth has reduced to less than half of 1991 and 2001 . The annual growth rate between 1991 and 2001 is 3.7 percent in Nagaur city was very high as compared to the district growth rate of 2.6 percent. But it was drastically reduced to 1.2 percent between 2001 and 2011 as compared to the district growth rate of 1.9 percent per year. In all three decades, the number of males has been more than the number of females. But interestingly, the percentage share of female in the total urban population is increasing continuously. With 46.24 percent in 
1991 and 47.45 percent in 2001 to 48.56 in 2011 . This data shows a trend towards gender equality in terms of urban population structure. (Figure- $3 \& 4$ )

Figure 1: Population

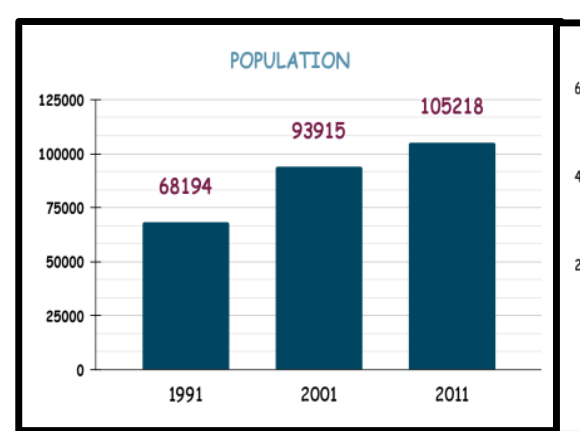

Figure 2: Male and Female

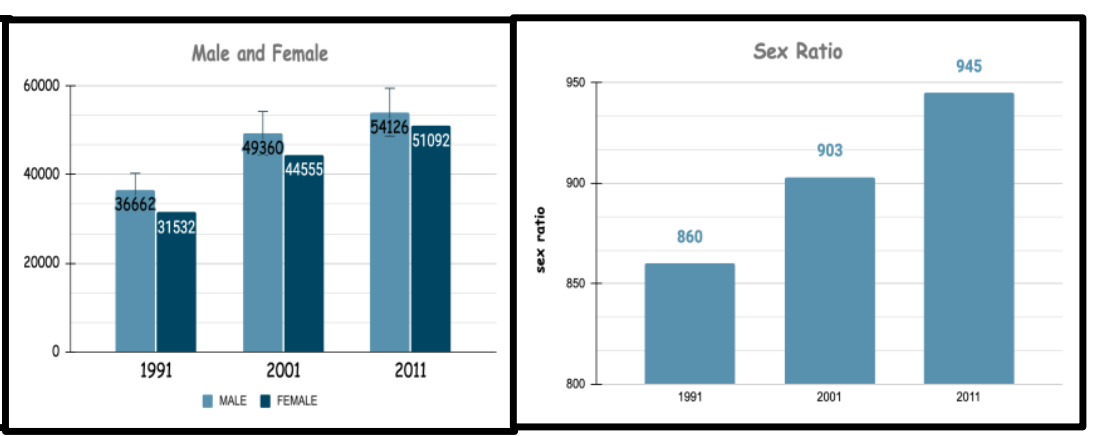

\section{Sex Ratio}

The status of women in an area can be understood through the sex ratio. The sex ratio of Nagaur city was 860 in 1991 which increased to 903 by 2001 and further to 945 by 2011 . Though it is still less than the sex ratio of the district which was 950 in 2011, year after year there has been a radical change in the sex ratio of Nagaur city, and in a period of 20 years (1991 to 2011), Nagaur city has improved by 85 points in terms of sex ratio. Which is a good sign of gender equality. (Figure-2)

\section{Number of Households}

A group of persons who cook food in the common kitchen is called a household. The number of households increased from 10,804 in 1991 to 14,705 in 2001, which further increased to 18,301 in 2011. The increasing number of households is indicative of an increasing trend of urbanization. As the number of households lights up, the population will also increase continuously. Although the number of households in Nagaur city is less as compared to other big cities of the state. (Figure-6)

\section{Population Density}

Population density refers to the number of people living per unit area. The area of Nagaur city is $37.8 \mathrm{~km}$. There is a continuous increase in population density, whose effect is being visible on land-use change and excessive resource consumption. In 1991, the population density of Nagaur city was 1,804 per square kilometre, which in 2001 increased to 2,340. Similarly, this growth continued and by 2011 the population density increased to 2,782. The density of Nagaur city is many times more than the density of Nagaur district. According to the 2011 population, the density of Nagaur district was 187 people per square km. (Figure-5)

\section{Slum Population}

Slums are defined in the census as areas that are unfit for human habitation and are characterized by overcrowding and poor arrangement and design of buildings, the narrowness of roads, lack of ventilation, lack of sanitation facilities, and safety and health. There has been a steady increase in the number of slums in the last decades, where the percentage of slums was 3.19 percent in 1991, it went up to 8.40 percent in 2001 and it is a matter of concern that it continues to increase further. By 2011, it reached 11.51 percent of the total population of the city. The life of the people living in the slums has been degraded by the unhealthy impacts of urbanization and there are few facilities available in these areas of the city which is a matter of concern for urban management. The growth of slums raises serious questions on urban management, without any management slums can prove to be an urban disaster.(Figure-7) 


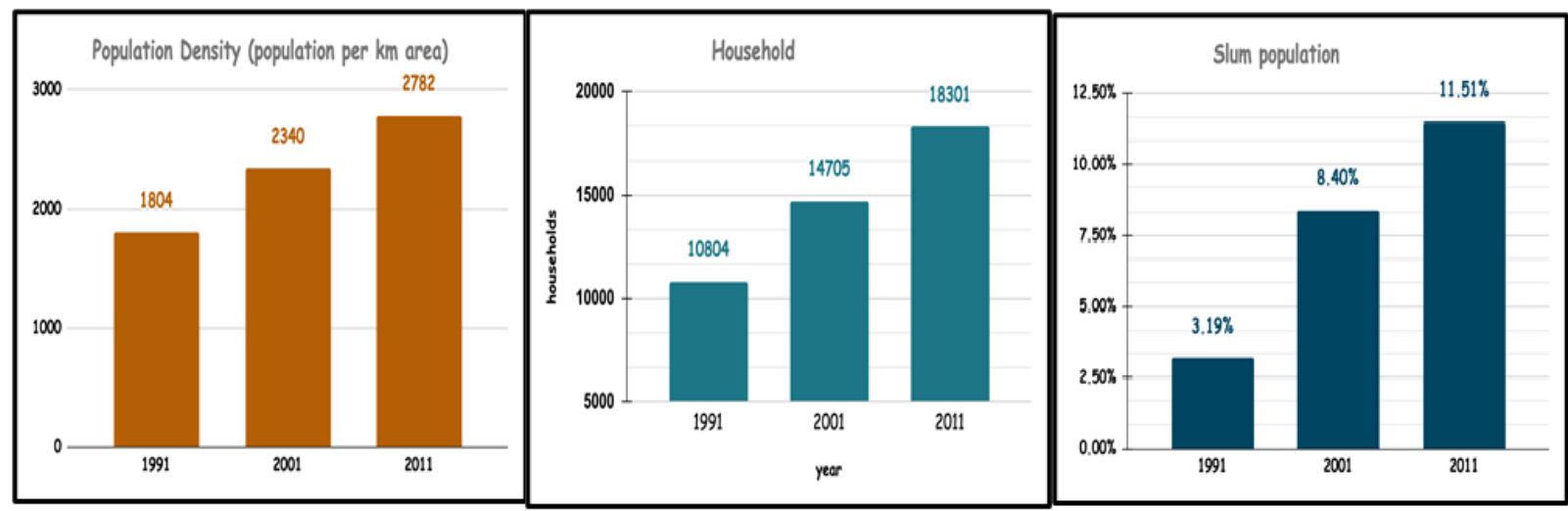

\section{Literacy Rate}

The literacy rate of the population is defined as the percentage of literates in the age group of seven years and above. A person who can read, write and understand any language is considered literate. A person who does not possess any one of these abilities is not literate. To be literate it is not necessary whether a person has received formal education or not. All children aged 6 and under are considered illiterate even if they are going to school and have learned to read and write. There has been a drastic change in the literacy rate between 1991 and 2001. During this period, where the literacy rate was 57.47 in 1991 , it increased to 66.09 percent in 2001 . Which continued to grow like this to 70.68 percent by 2011 , whereas if we compare it with the district level, then it is much higher than the district literacy rate, which was 62.80 percent. The change in literacy rate between 1991 and 2001 is appreciable, but in Nagaur city, it slowed down for the next decade. It has to be noted that while the growth of literacy rate was to increase over time, on the contrary, it has decreased in Nagaur city. If the literacy rate is studied from a gender perspective, it was seen that there has been a considerable change in male literacy between 1991 and 2001, but after that, the male literacy rate has remained almost the same between 2001 and 2011. There has been a spectacular improvement in the female literacy rate, from 40 percent in 1991 to 56 percent in 2001. An increase of about 22 percent reflects an appreciable improvement in the educational level of women. The female literacy rate increased to 61.13 percent by 2011 . If we talk about the difference between female and male literacy, then it has decreased in a big way between 1991 and 2011, where according to the 1991 population, the literacy gap between males and females was 30.71 percent, which further decreased to 25.05 percent in 2001. But it is a matter of concern that even in 2011, this gap of literacy between men and women remained 18.66 percent. Bridging this gap will prove to be a major challenge for urban administration in the coming decades. (Figure-8,9 \&10)

\section{SC \& ST Population}

A person is identified as a member of a Scheduled Caste or a Scheduled Tribe based on with time the prescribed lists of SC \& ST as per the SC \& ST (Amendment) Order, 1976 issued by the President of India. Scheduled Castes can be from among Hindus or Sikhs or Buddhists only while a member of a Scheduled Tribes can profess any religion. If the person belonging to a Scheduled Caste or Scheduled Tribe has returned to his/her caste or tribe, it is reckoned as Scheduled Caste or Scheduled Tribe only if that name finds a place in the prescribed list. If we talk about Schedule Caste and Scheduled Tribe population, then it will be worth noting that there is a considerable population of Scheduled Castes in Nagaur city but the population of Scheduled Tribes is very less. The proportion of SC population to the population of the entire city has been around the same 13 percent in all three decades. On the other hand, the population of Scheduled Tribes has been less than 1 percent in all three decades. 


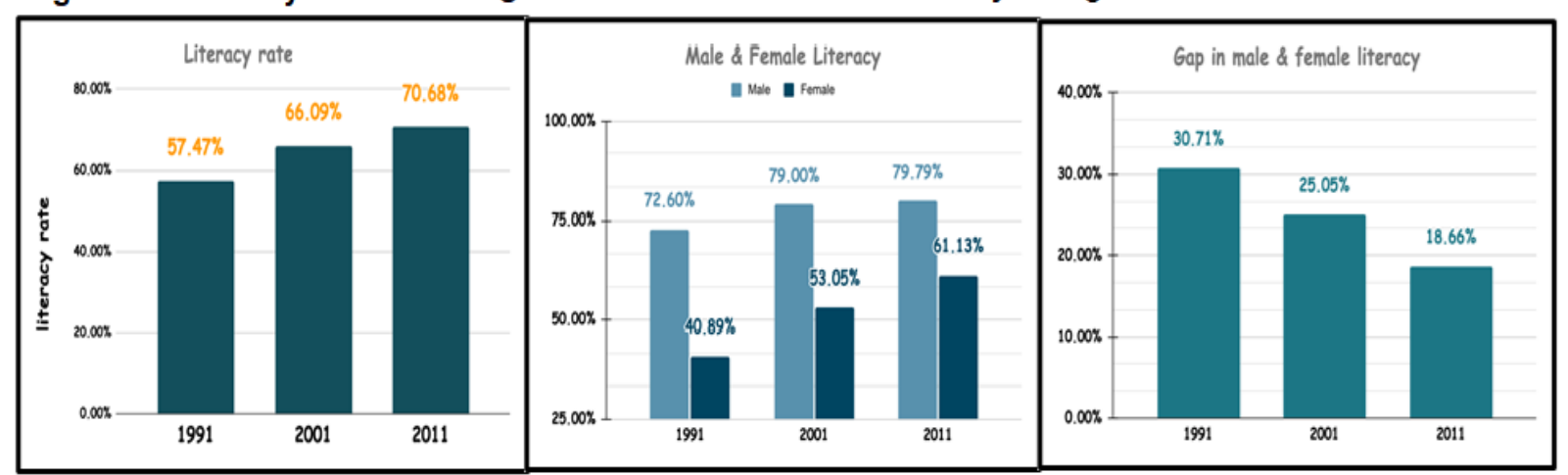

\section{Work Participation}

Work is defined as participation in economically productive activities. Such participation may be of a mental or physical nature. Work involves not only physical work but also supervision. It may include unpaid support for a farm, family enterprise, and any other economic activity. All the persons engaged in the work are called workers. The city has witnessed a fluctuating trend in work participation. A person who has worked for 6 months or more during the last one year is called the main worker. A person who works for less than six months in economic activity is called a marginal worker. A person who has not worked for a single day during the previous year is called a non-worker. If we look at the work participation structure of Nagaur city, then we will find that most of the population comes under the non-worker category and less than 30 percent of the population participate as main workers in the economy. If we talk in exact terms, the work participatory scenario of 1991 shows that about 26.2 percent of the personnel were in the main category. which increased to 26.4 percent by 2011. The proportion of marginal workers is increasing continuously which was 0.5 percent in 1991 and reached 1.2 percent in 2001 and according to the 2011 census, about 4 percent of workers are in the marginal category. The above data clearly shows the decadal change in work participation where the majority of the population is outside work participation. It is worth noting that a large number of human resources are deprived of employment, which cannot be a sign of a good city in terms of economics. Because one of the factors driving urbanization is the availability of employment. This data calls for changes in the city's work participation and economic landscape with immediate effect. (Figure-11,12 \&13)

Figure 11: Work Part., 1991 Figure 12: Work Part., 2011 Figure 13: Work Part., 2021

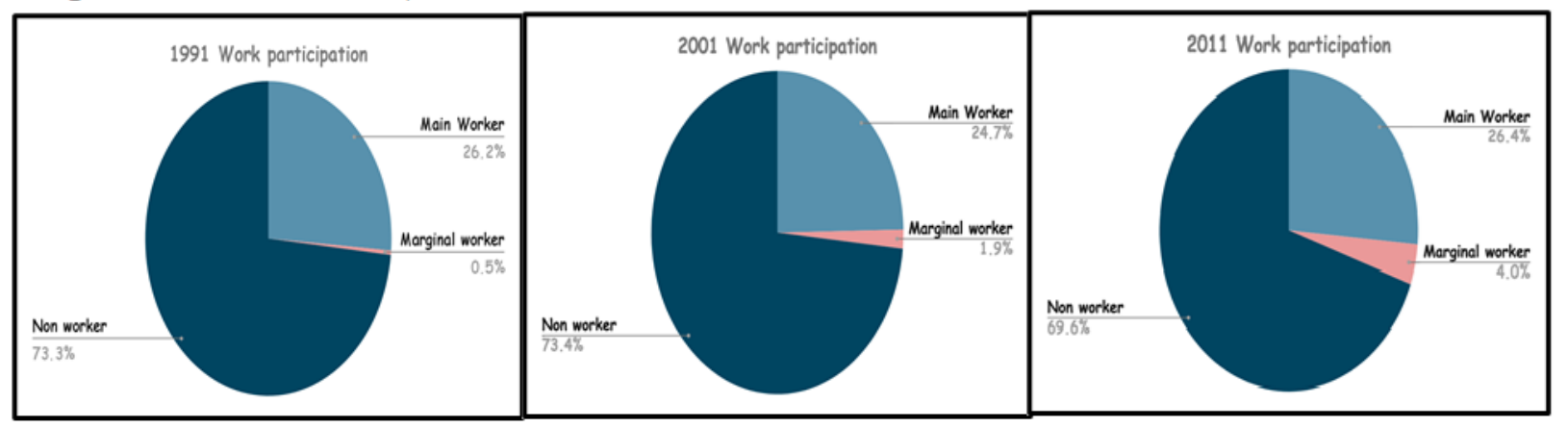

\section{Economic Activity of Urban Population}

If we look at the economic activities of the people participating in the labour force, we will find that in 2001, 3.4 percent of the labour force was made up of cultivators, 1 percent were agricultural workers and 11 percent were household industry workers. At the same time, 84.2 percent of the people were engaged in other work in which the service sector plays an important role. The service sector has been the main employment generating sector. A person engaged in farming 
on his personal or govt land is called a cultivator. Similarly, a person working on another person's land for wages in cash is called agricultural labour. The head and other members of the household engaged in an industry operating within the premises of a house are called household industry workers. Other workers include all those workers who do not fall under the above three categories, such as government employees, municipal employees, teachers, doctors, entertainers, etc. If we talk about the economic activities of 2011 , then 5.7 percent of the total population participating in the labour force were cultivators, 4.1 percent were agricultural workers and 9.2 percent were domestic industrial workers, 81 percent were engaged in other work. Mainly hand tools, edible oil, and gypsum powder are manufactured and exported. The work of making hand tools made of iron is traditionally done in Nagaur city. A noticeable aspect of workforce participation is that the participation of women in the labour force is very low, according to the 2011 population, only 17 percent of women were part of the labour force. (Figure-14\&15)

\section{Figure 14: Economic Activity of Urban Population, 2001}

\section{Figure 15: Economic Activitv of Urban Population, 2011}

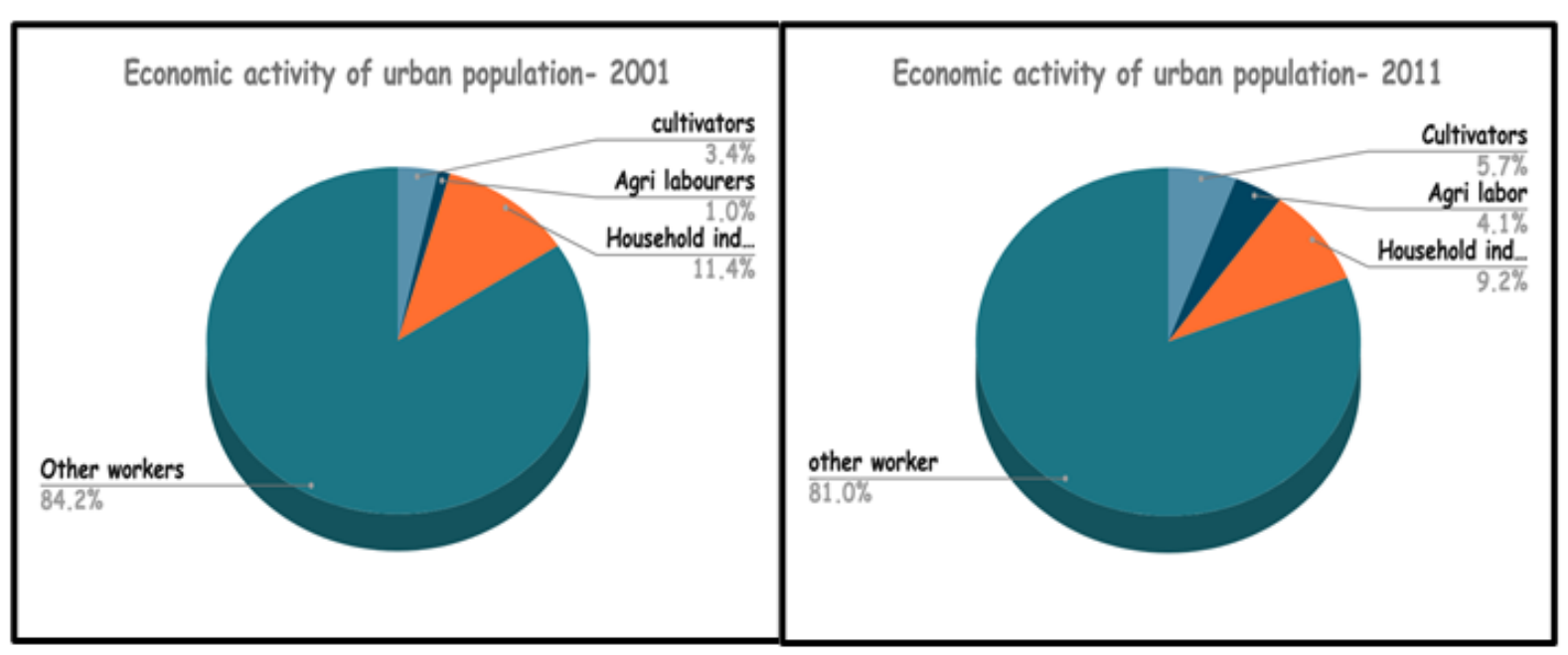

\section{Outgrowth}

Towns spread in continuity with the city are called outgrowths. Till 2001, the outgrowth of Nagaur city consisted of Mansar and Chenar villages, with the passage of time in 2011 the outer periphery of Nagaur increased and its expansion has included some more towns like Tausar, etc. With the rapid expansion in the periphery of Nagaur, it can be said that in the coming time, big towns like Basni, Kumhari, Gogelao, Balwa will also be included in its periphery. The increase in outgrowth reflects the spatial expansion of Nagaur city which continues to grow outwards.

\section{Conclusion}

A lot of studies and research work have been done at the international, national, and regional levels on this topic. Land Use and Land Cover of urban areas are changing rapidly and the effect of urbanization can be seen in our urban spaces. Thus, to develop our urban society sustainably, we need to study the trends of urbanization in Nagaur city. The evidence-based scientific study will be useful in visualizing the actual picture of urban expansion. There is an urgent need to take some serious effort related to studying the area. We have seen that a common model for trends and patterns of urbanization in smaller cities has not been developed so far. The detailed studies related to trends and patterns are largely conducted for million-plus cities. In-depth studies of comparatively smaller cities are very less in number. When we see that 70 percent of our population lives in class $1 \mathrm{UAs} /$ Towns, out of which Nagaur is also one. It is necessary to study them to understand the real situation of urbanization. Our approach has been that we wake up after things go wrong. This needs to be changed, and we have to plan our cities according to 
scientific and technical studies to achieve the Sustainable Development Goals designed by the United Nation. Sustainable Development Goal 11 is to "Make cities inclusive, safe, resilient and sustainable". This target cannot be achieved by a top-down approach. We need to focus on every city and we have to plan our cities accordingly. The local phenomenon must be considered to make any policy, related to an urban area. Unfortunately, Nagaur district is a less researched region in this field. The effects of urbanization can be easily seen in Nagaur district and with academic intervention, we can build a sustainable, resilient city. To save our cities from becoming an urban disaster, we need to take some academic initiatives.

Through this paper, we found that urbanization is spreading rapidly in Nagaur city and various trends of urbanization are indicating to pay attention to it with immediate effect. According to the 2001 population, the outgrowth of Nagaur city was limited to Manasar and Chenar towns, but by the year 2011, Tausar and other nearby towns have also been included in it. With the increase of population in the city of Nagaur, many new urban facilities have emerged, but because of the current growth, these facilities can be said to be inadequate. Although the pace of urbanization in Nagaur city has decreased from 2001 to 2011 compared to the last decade 1991 to 2001, yet the current change in urbanization is putting serious pressure on the urban resources like land, infrastructure facilities. In the recent trend of urbanization, there are signs of gender inclusion, yet it is far from the goal of gender equality, whether it is the share of women in the population or the sex ratio and literacy rate, we are still lagging in giving women equal participation to men. The increasing number of vehicles have put great pressure on the city's roads, the present road infrastructure is unable to cope with the increasing transport pressure. There is a need to improve urban facilities at the same pace as urbanization is increasing. It is clear from this trend analysis that the city of Nagaur has seen promising growth in literacy rate and sex ratio in the last few decades, but it will be a challenge to keep this rate going forward. Increasing population in slums will become a serious challenge in the coming times, to deal with it, emphasis will have to be given to an adequate amount of urban housing and facilities. Thus, it can be said that while urbanization is providing new opportunities in Nagaur city, on the other hand, the challenges in its sustainable growth cannot be denied.

\section{Reference}

1. Davis, K. (1965). The Urbanization of the Human Population: Scientific American. In The City Reader (pp. 1-11). Routledge London.

2. District Census Handbook, Village, and Town Wise Primary Census Abstract (PCA), Nagaur(No. 09). (2006). Directorate of Census Operation, Rajasthan.

3. Dadhich, P. N., \& Hanaoka, S. (2011). Spatio-temporal urban growth modelling of Jaipur, India. Journal of Urban Technology, 18(3), 45-65.

4. District Census Handbook, Village, and Town Wise Primary Census Abstract (PCA), Nagaur (No. 09). (2014). Directorate of Census Operation, Rajasthan.

5. Roy, P. S., Roy, A., Joshi, P. K., Kale, M. P., Srivastava, V. K., Srivastava, S. K., \& Sharma, Y. (2015). Development of decadal (1985-1995-2005) land use and land cover database for India. Remote Sensing, 7(3), 2401-2430.

6. United Nations, Department of Economic and Social Affairs, Population Division (2018). The World's Cities in 2018-Data Booklet (ST/ESA/ SER.A/417).

7. United Nations, Department of Economic and Social Affairs, Population Division (2019). World Urbanization Prospects: The 2018 Revision (ST/ESA/SER.A/420). New York: United Nations.

8. https://nagaur.rajasthan.gov.in/content/raj/nagaur/en/home.html\# 